\title{
Urban open spaces from a dispersal perspective: lessons from an individual-based model approach to assess the effects of landscape patterns on the viability of wildlife populations
}

\author{
Homero Marconi Penteado ${ }^{1,2,3}$ (D) \\ Accepted: 17 November 2020 / Published online: 25 November 2020 \\ (C) The Author(s) 2020
}

\begin{abstract}
Green areas drawn on a city plan represent open spaces that have different meanings for humans and wildlife. Diverse kinds of green may influence species viability in urban environments. It is necessary to understand what those areas mean for wildlife populations and how land-use changes affect habitats and movements for making scientifically defensible planning and design decisions. My objective was to demonstrate how open space and urban development patterns affect the viability of wildlife populations in urbanizing landscapes from a movements perspective. Eight scenarios for 2060 for an urbanizing area near Portland, Oregon combined four open space (none, corridors, parks, and network) with two urban development patterns (compact and dispersed). Dispersal model HexSim simulated three target species - Red-legged frog (Rana aurora aurora), Western meadowlark (Sturnella neclecta) and Douglas squirrel (Tamasciurus douglasii) - movements on those scenarios to compare and contrast sustained populations to the ca. 2010 baseline landscape. Network scenarios presented the largest number of frog breeders. Greenway scenarios showed the largest populations of squirrels. Park and network scenarios sustained viable populations of meadowlarks, but park scenarios performed best. Compact development scenarios performed best for most indicators, while dispersed development scenarios performed better for meadowlarks. Network scenarios performed best when considering the collective of species. Networks presented more diverse habitats, sustaining higher diversity of species. For plans to sustain more species, more comprehensive and diverse habitats must be promoted, otherwise trade-offs should be expected - like the extinction of meadowlarks in greenway scenarios.
\end{abstract}

Keywords Urban open space · Wildlife population viability $\cdot$ Spatial concepts $\cdot$ Alternative future scenarios $\cdot$ Dispersal model . HexSim

\section{Introduction}

Urban planning is a complex endeavor where open space is one of many subsystems of concern. Others include transportation, economic development, housing needs, public health and water supply (Forman 2008). Planning of new urban

Homero Marconi Penteado

homero.marconipenteado@wur.nl

1 Department of Landscape Architecture, School of Architecture and Environment, College of Design, University of Oregon, E 13th Ave, OR 97403 Eugene, USA

2 Departamento de Arquitetura e Urbanismo, Universidade Federal do Espirito Santo, Vitória, Brazil

3 Present address: Department of Environmental Sciences, Landscape Architecture and Spatial Planning, Wageningen University and Research, Droevendaalsesteeg 3, 6708PB, Wageningen, Netherlands zones customarily involves deep understanding of cultural and socioeconomic systems, but open spaces are not always among the top priorities. While open spaces have gained importance in urban planning in recent decades, they have generally emphasized human, not wildlife, use. Commonly, biodiversity is not one of the main dimensions of physical planning (Forman 2008). When biodiversity is addressed, planners usually indicate natural areas, areas of high habitat value to protect or restore, areas that are sensitive or are at risk, and areas to be acquired in the future (Metro 1992), generally depicted as green areas on a map, as can be seen in several examples of open space planning (Metro 1992; Calthorpe and Fulton 2001; Rottle and Maryman 2006).

Landscape ecology offers a knowledge basis for spatial planning (Ndubisi 2002; Termorshuizen et al. 2007). It has been increasingly adopted as a scientific basis for planning open space systems and greenways. Landscape ecological principles can be translated into spatial concepts. These are 
diagrammatic expressions of principles used by landscape architects and planners to organize ideas and communicate prescriptions for future landscape change. Spatial concepts have been adopted in physical planning proposals in several cities and metropolitan regions, such as Forman's approach to metropolitan planning in the Barcelona Region (Forman 2004; Forman 2008). His proposal for open space includes a plan of nature in the Barcelona Region clearly based on land mosaics theory (Forman 1995). However, Steinitz indicates that there are gaps between landscape ecology and landscape planning (Steinitz 2001), while Botequilha Leitão and Ahern defend that there is a need for methods that strengthen the potential contributions between landscape ecology and landscape architecture (Botequilha Leitão and Ahern 2002). This study offers conclusions on deepening the links between landscape ecology and landscape architecture.

Urbanization is one of the major causes of habitat loss and fragmentation, which directly affects the ability of wildlife species to disperse and maintain viable populations (Opdam et al. 2006; Schumaker 1996). Predicting animal population response to land-use changes is critical to making wellinformed decisions (McRae et al. 2008). This article demonstrates a modeling approach for evaluating the effects of future open space and urban development configurations on wildlife species persistence in urbanizing landscapes. I evaluated eight scenarios for an area of future metropolitan expansion in Portland, Oregon. Scenarios for the year 2060 were depicted in geographical information system (GIS) maps, and combined four patterns of open space with two patterns of urban development. Principles of landscape ecology informed the proposition of spatial concepts, which were the basis for producing open space and urban development patterns in the future scenarios (Penteado 2013). The work reported here focuses on landscape ecological spatial concepts that support biodiversity conservation (Dramstad et al. 1996; Forman and Collinge 1997; Ahern 1999; Botequilha Leitão and Ahern 2002; Opdam et al. 2006).

I used an Individual-Based Model (IBM), HexSim, to assess the viability of populations of three wildlife species that are likely to be affected by urbanization in the study area and have contrasting habitat preferences: Northern red-legged frog (Rana aurora aurora - henceforth, Red-legged frog), Western meadowlark (Sturnella neglecta), and Douglas squirrel (Tamiasciurus douglasii).

Several studies have applied dispersal models to evaluate the effects of habitat arrangement on persistence of wildlife species at different scales and contexts (Calkin et al. 2002; Hulse et al. 2002; Schumaker et al. 2002; Carroll et al. 2003; Carroll et al. 2004; Schumaker et al. 2004; Heinrichs et al. 2010; Stronen et al. 2012; Marcot et al. 2013; Bancroft et al. 2016; Wiens et al. 2017; Ward et al., 2020; Dunk et al. 2019; among others). Others modeled the effects of combined a model of climate change on animal populations (McRae et al. 2008; McCauley et al. 2017; Nogeire-McRae et al. 2019). However, none of these studies address urban environments, or landscapes undergoing rapid urbanization, despite the importance of urban open space for biodiversity (Callaghan et al., 2019).

In summary, my study explores the consequences of the choice of open space configuration and urban development patterns for wildlife populations. My goal is to test an approach able to provide landscape architects and planners with quantitative information to compare among alternatives for the future of a region and to make well-informed land-use planning decisions that affect persistence of wildlife species.

\section{Methods}

This modeling approach combined land-use and land-cover configurations with wildlife population dynamics. First, I chose a region that has predicted urbanization until 2060. I then chose three species that urbanization in that region is likely to affect. I produced eight scenarios of open space and urban development that present distinct landscape patterns (Penteado 2013) using computer software Envision to produce 20 rule-based replicates of each scenario, resulting in varying habitat quantities. A land-use land cover map for each scenario mean replicate was converted to habitat suitability maps for each of the three species (Schumaker et al. 2004, Baker and Landers, 2004, Hulse et al., 2002). I used those suitability maps and species' life history parameters with individual-based model HexSim to develop dispersal models and evaluate the effects of the various landscape arrangements on individual dispersal and resulting populations. The following sections describe these steps.

The goal was to produce simulations that were complex enough to capture the influence of landscape patterns on the ability of animals to move across the landscape to establish territories and breeding habitats, but simple enough to be incorporated in open space planning.

\section{Study area}

I applied this framework to two areas designated for future urban expansion adjacent to Damascus, OR, in the southeastern portion of the Portland metropolitan region (Fig. 1a and b). Their areas sum 1879 ha. An $800 \mathrm{~m}$ buffer surrounding those areas was added to provide connections among them and to adjacent habitats (Fig. 1c). The total area used in the simulations sums to $4592 \mathrm{ha}$. The study area presents a highly fragmented landscape (ca. 2010). There was a significant alteration of pre-settlement habitats once composed of forests, woodlands, and savannas. Low density rural residential areas and agricultural fields prevail among patches of forest, oak savanna, and grassland; a few small, isolated wetlands occur 


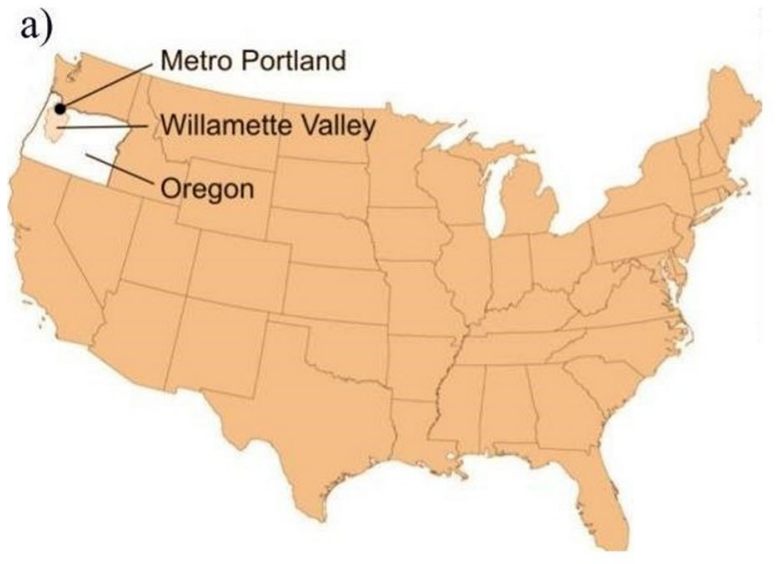

b)

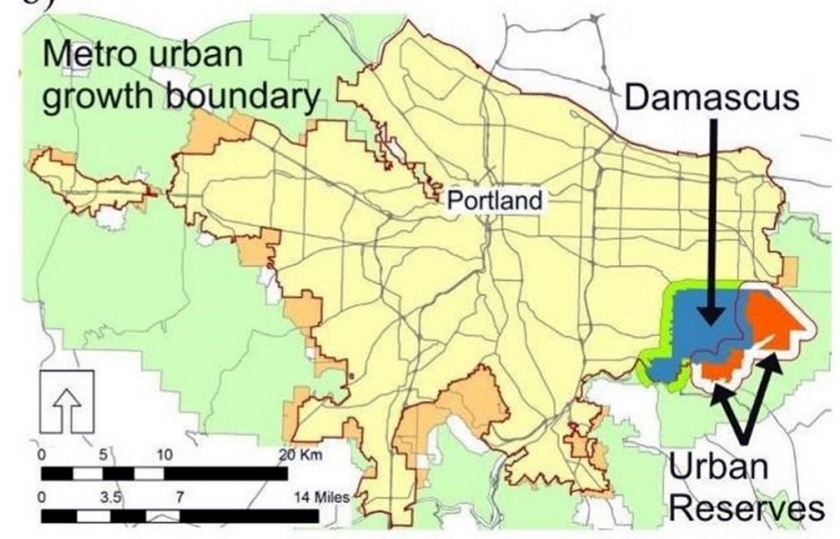

Fig. 1 Study area a) within continental United States; b) within the metropolitan region: urban reserves are areas where metropolitan expansion should happen in the next 50 years (red); c) ca. 2010 land-

in the area; riparian vegetation is at various degrees of degradation along the North Fork Deep Creek (Fig. 1c).

\section{Wildlife species}

This study targets three wildlife species that require various habitat types that may be affected by urbanization. The Redlegged frog (Rana aurora aurora) is associated with wetlands for breeding and moist forests for seasonal migration. Redlegged frogs disperse to relatively large areas and require close association with moist forests, stream banks, and wetlands (COSEWIC 2004). They typically breed in vegetated shallows of wetlands, ponds, ditches, springs, marshes, margins of large lakes, and slow-moving portions of rivers. They could also breed in ephemeral ponds, moist house yards and neighborhood parks where building density is low, as well as in small natural or modified catchment areas used for storage of stormwater run-off (Chelgren et al. 2006; COSEWIC 2004; Davidson et al. 2001; Lannoo 2005; O’Neil 2001). Habitat fragmentation is of particular concern in view of the c)

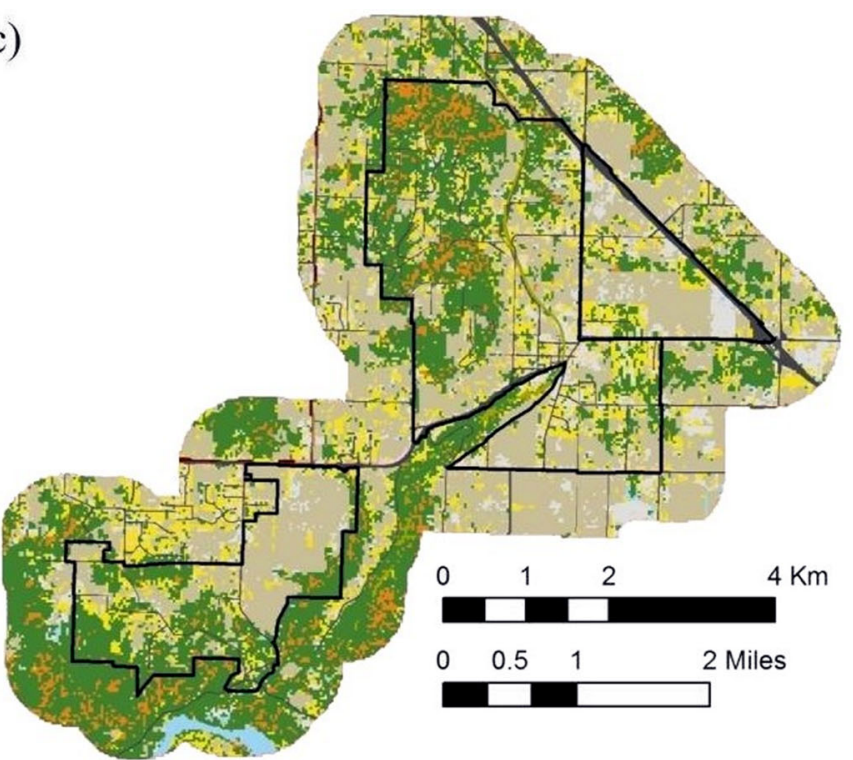

Urban_Reserves

Residential 0-4 DU/ac; 16

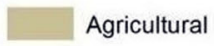

Residential 4-9 DU/ac

Residential 9-16 DU/ac

Residential >16 DU/ac

Residential 16 DU/ac - Commercial

Commercial

Commercial - Industrial

Industrial

Sand and Gravel

Civic Open Space

Roads

Water / Wetlands

Forests

Oak savanna

Natural grassland and shrub

use and land cover representation of the area addressed in the dispersal model

species' seasonal migrations between forested areas and wetland breeding sites (COSEWIC 2004).

Western meadowlarks (Sturnella neglecta) breed and feed in relatively large expanses of grasslands and prairies, but flocks sometimes feed on corn, wheat, and other grains (Morrison 1993; Oregon Department of Fish and Wildlife 2006). Declines of grassland bird populations result from loss (urbanization), degradation (land management practices, disruption of natural disturbance regimes), and fragmentation (smaller isolated patches) of habitat (Johnson and Igl 2001; Oregon Department of Fish and Wildlife 2006).

Douglas squirrels (Tamiasciurus douglasii) associate with conifer forests ranging from west of the Cascade Mountains to the coast, from southern British Columbia, Washington, Oregon, to northern California. In general, old-growth stands are preferred over young and mature stands, although studies have shown larger abundance in second-growth or mature stands (Ransome and Sullivan 2004). They feed on seeds, fungi, and occasionally bird eggs and nestlings; food supply determines population fluctuations (Gonzales et al. 2008; Sullivan and Sullivan 1982). Douglas squirrel is highly 
territorial and solitary, except during mating. Home range is less than 0.6 ha. Migration may occur if food supply diminishes (O’Neil 2001).

By selecting a suite of target species, planning measures to support them may also influence viability of other species with similar requirements (Rubino and Hess 2003). For example, the Red-legged frog may share habitats with Northwestern salamanders, Long-toed salamanders, Pacific chorus frog, and Rough-skinned newts (Lannoo 2005). The Western meadowlark may coexist with other grassland birds such as Western bluebird, Oregon vesper sparrow, Horned lark, Grasshopper sparrow, and Common nighthawk (Oregon Department of Fish and Wildlife 2006). Douglas squirrels share habitats with other tree squirrels such as the Northern flying squirrel and the Townsend chipmunk, and may indicate the presence of their predators such as the Northern spotted owl, goshawk, and weasel (Duncan 2004).

\section{Alternative future scenarios}

Future scenarios depart from a ca. 2010 representation of the study area's existing conditions. Eight future scenarios for the year 2060 combine four open space patterns (no specific open space pattern, corridors, patches, and network) and two urban development patterns (compact and dispersed) (Penteado 2013). Planning rules using principles of landscape ecology for corridors, patches and networks, and compact and dispersed urbanization patterns determined the landscape arrangement present in the eight scenarios.

All scenarios assume at least a set of minimum habitat conservation strategies: areas within a $60 \mathrm{~m}$-wide buffer around streams, mature and old growth forests, wetlands, grasslands and oak savannas were protected from development. In those areas, modeling incorporated automatic processes to simulate vegetation succession. The different open space patterns used in scenarios contrast and test landscape patterns intended to support species movements via 1) increased corridors to connect habitat patches; or 2) increased patch size and distribution both to increase total habitat area and to serve as stepping stones for movement; or 3) a combination of increased habitat patch sizes and area with corridor connections; or 4) neither increased patches or corridors.

Greenway scenarios emphasize corridors and strategies for protecting and restoring riparian vegetation. Streams create a framework for promoting an armature of open space that provide habitat and connectivity. Park System scenarios adopt parks as a means to create larger habitat patches and stepping-stones. These scenarios test the ability of the chosen species to move through a fragmented landscape where there are fewer connecting habitat corridors. Network scenarios combine habitat patches, stepping-stones and corridors to protect and connect habitats for the chosen species and consequently protect biodiversity (Opdam et al. 2006).
Compact development scenarios depict urbanization strategies for built land uses that concentrate development around existing transportation corridors, in areas of lower ecological impact. Urban development in these scenarios has higher proportions of high-density residential and mixed uses (residential and employment) to minimize loss of open space and maximize ecological function to the year 2060. Dispersed development scenarios reproduce existing trends in urban development (large-parcel, single-family, lower densities), which occur, in the simulations, in any developable areas except those where habitat conservation is a priority.

The combinations of open space and development produce, then, the following scenarios: the first two, Compact Development (CD); Dispersed Development (DD), had no open space concept adopted; Greenway and Compact Development (GCD) and Greenway and Dispersed Development (GDD) adopted corridors; Park System and Compact Development (PCD) and Park System and Dispersed Development (PDD) focused on the distribution of habitat patches; and Network and Compact Development (NCD) and Network and Dispersed Development (NDD) combined corridors and patches.

The software Envision simulates a predefined human population growth and vegetation succession (Penteado 2013). Assumptions about open space and urban development patterns were translated into policies, then into rules that drove scenario simulations (Table 1). Combinations of policies produced the eight scenarios.

\section{Dispersal model}

I used computer software HexSim (version 2.5) to assess wildlife population viability from a dispersal perspective, which assumes organisms are in search of suitable territories to meet their life history needs. My aim was to build simple but scientifically defensible models that evaluate population viability in the endpoint landscapes (2060) of each scenario for the three chosen species.

HexSim is a spatially-explicit, individual-based computer model designed for simulating terrestrial wildlife population dynamics and interactions (Schumaker 2011, 2018). This model combines spatial landscape data with organism response to various land cover types to examine population viability (Stronen et al. 2012). HexSim couples species' habitat needs to their survival, reproduction and movement rates. HexSim evaluates the effects that spatial patterns may have on wildlife populations by testing the ability of individuals to disperse in the landscape.

HexSim uses species-habitat associations, area requirements, estimates of demographic parameters and movement characteristics, survival, reproduction, and movement information (Schumaker et al. 2004) (Table 2). Species population viability in HexSim is strongly based on the ability of 
Table 1 Examples of policies that translate spatial concepts to rules used in the simulations

\begin{tabular}{|c|c|}
\hline Policy 21 & COR2 Creation of underpasses for Red-legged frog in wetlands \\
\hline Policy goal(s) & Reconnect wetlands intersected by roads. Part of the road that is adjacent to a wetland converts to an underpass. \\
\hline Site attributes & UrIn $=1\{$ Inside Urban Reserve $\}$ and wtlnd $=5$ wetland $\}$ and ZONE $=20\{$ Roads $\}$ and OS $=0$ \\
\hline Outcomes & $\begin{array}{l}\text { Expand }(U r I n=1 \text { and wtlnd }=5 \text { and } Z O N E=20 \text { and } O S=0,110,000, A R A=26\{\text { Seasonal wetlands }\} \\
\text { and } O S=1233\{\text { Underpass for Red-legged frog }\}): 50\end{array}$ \\
\hline Policy 31 & BUF2 Protection of grasslands for western meadowlark \\
\hline Policy goal(s) & $\begin{array}{l}\text { Protect grasslands and provide areas for passive recreation. It applies to protection of conservation areas } \\
\text { created by policy CONS3 that creates protected grasslands. }\end{array}$ \\
\hline Site attributes & $\begin{array}{l}\text { UrIn }=1\{\text { Inside Urban Reserve }\} \text { and NextTo(OS }=1223 \text { \{Open space or natural area: grassland }\}) \\
\text { and OS }=0 \text { and LULC_X } !=86 \text { Natural Grassland }\} \text { and ZONE } !=20 \text { Roads }\} \text { and LULC_A } !=1\{\text { Urban }\}\end{array}$ \\
\hline Outcomes & $\begin{array}{l}\text { Expand(UrIn }=1 \text { and NextTo(OS }=1223) \text { and OS }=0 \text { and LULC_X } !=86 \text { and ZONE } !=20 \text { and LULC_A } !=1 \text {, } \\
\quad 600,000, Z O N E=14 \text { Restoration }- \text { non-developable }\} \text { and LULC_X }=86): 100\end{array}$ \\
\hline
\end{tabular}

individuals to move through the landscape for both foraging/ feeding and for dispersal to breeding locations. HexSim produced spatial data (HexMaps) and simulation results expressed in census tables (measures of population size through time) that contain population size data by replicate and time step. For Schumaker and Brookes (2018), the model adds more biological nuance to connectivity assessments.

For the dispersal model representations of the species in the modeled alternative future landscapes, I adopted a landscape classification composed of four elements: breeding habitats, movements and foraging habitats, agricultural matrix, and urban matrix. The representation attempted to echo both species life histories and land mosaics components - patch, corridor, and matrix - in a form sufficiently simplified to enhance its applicability within the time and resource constraints of a typical metropolitan open space planning process.

Landscape representations of scenarios in a geographic information system contained habitat scores, ranging from zero to ten, that reflect habitat quality for each species (Baker and

Table 2 Species parameters used in the simulations. Reproduction considers individuals that survive the 1st year (Red-legged frog: 5\% survive to metamorphosis; Western meadowlark: 50\% fledge; and

\begin{tabular}{|c|c|c|c|}
\hline & Red-legged frog & Western meadowlark & Douglas squirrel \\
\hline Breeding habitats & Wetlands & Savannas and grasslands & Old-growth and mature conifer forests \\
\hline Suitable habitats (migratory and non-breeding) & Moist forests & $\begin{array}{l}\text { Crops, grains, grass seed } \\
\text { rotation and pastures }\end{array}$ & $\begin{array}{l}\text { Low-density residential, parks, } \\
\text { open and hardwood forests }\end{array}$ \\
\hline Initial population & 300 individuals & 1000 individuals & 100 individuals \\
\hline Time steps/log period & $50 / 20$ & $200 / 50$ & $100 / 50$ \\
\hline Home range & less than 1 ha & 7 ha & less than 0.6 ha \\
\hline Reproduction (n) & 45 & 5 & Average 2 \\
\hline Dispersal & $<1.2 \mathrm{~km}$ & $>1.6 \mathrm{~km}$ & $<0.15 \mathrm{~km}$ \\
\hline Breeding strategy & Breeding affinity. & $\begin{array}{l}\text { Adults return to original or } \\
\text { adjacent to original territory. } \\
\text { Juveniles acquire new. }\end{array}$ & Juveniles acquire new area. \\
\hline Territorial & No & Yes & Yes \\
\hline
\end{tabular}

Landers 2004; Schumaker et al. 2004). I adopted those scores to produce suitability maps for each species (Online supplementary material). Hence, each scenario generated three suitability maps, one for each species that I then converted into bitmap representations (see supplementary online material for suitability maps for ca. 2010 and all scenarios). These maps originated hexagonal representations (HexMap) that HexSim uses to simulate life-cycle events. Each hexagon is $30 \mathrm{~m}$ wide. The hexagonal grid facilitates movements to adjacent hexagons in multiple directions. HexMaps contained a simplified representation of the landscape; four land cover categories represented the landscape: breeding habitats, suitable nonbreeding habitats (for foraging and dispersal), urban matrix (which includes all roads), and rural matrix. Urban matrix hexagons received higher mortality rates to impose a higher stress on moving individuals.

Twenty HexSim simulation replicates for ca. 2010 and for each of the eight 2060 combinations of open space and urban development patterns were conducted for 50 (Red-legged

Douglas squirrel: $25 \%$ survive first year) to improve processing time. Report logging period starts after populations reach steady state 
frog), 100 (Douglas squirrel) and 200-year (Western meadowlark) simulation periods (time steps in the model). During modelling calibration, it was necessary to use different time frames for each species to allow populations to reach a steady state. Simulations started with populations in breeding sites. I used different numbers of individuals for each species. Because there was a small amount of wetlands in the area, I used a starting population of 300 Red-legged frogs to make sure most wetlands were populated. I used the same strategy for the Western meadowlark but with a larger initial population (1000 individuals). Douglas squirrel habitats were abundant in the ca. 2010 landscape. Its initial population was smaller (100) in order to observe their ability to move across the landscape and colonize habitats in the ca. 2060 future scenario landscapes.

\section{Evaluation}

I measured population viability by looking at population sizes that resulted from the capacity of the landscape to facilitate or impede species dispersal. I then explored wildlife habitat effects of urban open spaces in the 2060 scenarios, by contrasting them with the same qualities in the ca. 2010 landscape. I tracked two categories of population, breeding individuals and floaters (individuals that disperse in the landscape in search of breeding habitats), and used population size mean estimates across the multiple replicate simulations to compare across scenarios (Carroll et al. 2003; McRae et al. 2008; Stronen et al. 2012). Increases and/or decreases of breeding populations indicate the ability of those landscapes to sustain populations of the chosen species as a function of habitat arrangement and can be compared across scenarios. Comparing resulting populations (census) for each species for each scenario shows which spatial concepts were more effective in providing conditions for dispersal. By looking at breeders and floaters, I could also look at the influence of different types of habitats - habitats that are used for breeding and habitats that are used for movements respectively. I used a two-way ANOVA to test the interaction between open space and urban development patterns and a Tukey test to perform multiple comparisons of means with a $95 \%$ family-wise confidence level. Both tests used statistical software $\mathrm{R}$ version 2.14.1 (The R Foundation for Statistical Computing 2011).

\section{Results}

The effects of the combination of open space and development spatial concepts were significant on most scenario's breeding individual's and floater's means for all three species (interaction $p<0.05$ ). Park and network spatial concepts produced small differences $(p=0.66)$ in Western meadowlarks breeding individuals. Development spatial concepts (compact and dispersed) produced significant differences among most scenario means. Exceptions were floaters between the Redlegged frog's greenway scenarios $(p=0.95)$, Park and Dispersed Development (PDD) and Greenway and Compact Development (GCD) scenarios ( $p=0.35$ ), and between PDD and Greenway and Dispersed Development (GDD) scenarios $(p=0.95)$ (Fig. 2b).

\section{Red-legged frog}

Network and Compact Development (NCD) scenario presented the largest increases, followed by Network and Dispersed Development (NDD) and PDD (Fig. 2a and b). PDD had a small increase of breeding individuals compared to 2010, but the number of floaters decreased. Future scenarios employing no open space spatial concept (Compact Development (CD) and Dispersed Development (DD)) and greenway scenarios presented reduced populations of both breeding individuals and floaters, but those were comparable to 2010 quantities. Most compact development scenarios presented larger numbers of breeding individuals and floaters than dispersed development scenarios. Greenway and Dispersed Development (GDD) scenario had a slightly larger number of breeding individuals than Greenway and Compact Development (GCD); both scenarios had small differences in floaters $(p=0.95)$. There were also small differences between GCD and Park and Dispersed Development (PDD) floaters and GCD and PDD floaters. Relative to 2010, the DD scenario had the largest reductions.

The baseline landscape (ca. 2010) showed a population of 647 breeding individuals and 22,347 floaters. In the future scenarios, breeding individual means ranged from 593 (DD) to 942 (NCD) individuals. Floaters ranged from 19,734 (DD) to 30,427 (NCD) individuals.

\section{Western meadowlark}

The simulations of the existing landscape (ca. 2010) indicated that there are patterns that may sustain a small viable population of breeders. The baseline landscape (ca. 2010) showed a population of 21 breeding individuals and 62 floaters. Scenarios with no open space spatial concept (CD and DD) and greenway scenarios (GCD and GDD) were not able to sustain Western meadowlark populations (Fig. 2c and d). The initial population (1000 individuals) steeply dropped to extinction after a few time steps. Park and network scenarios presented reduced populations of breeding individuals compared to ca. 2010 but larger populations of floaters in dispersed development scenarios. Compact development scenarios presented significantly smaller populations for both indicators than dispersed development scenarios. Park and network patterns showed little influence in determining differences of breeding individuals, but 
a) Red-legged frog: Group members
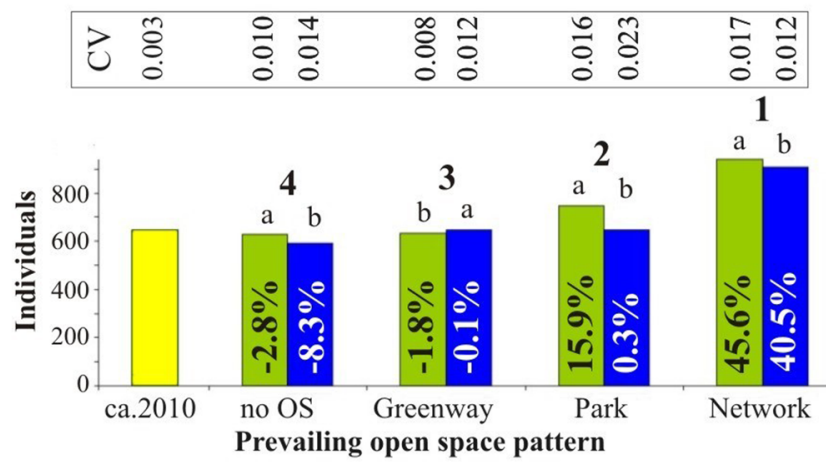

c) Western meadowlark: Group members

\begin{tabular}{lllll}
\hline \multirow{2}{0}{0} & $\hat{0}$ & $\hat{0}$ & 0 & 0 \\
0 & 0 & 0 \\
0 & 0 & 0 & 0
\end{tabular}

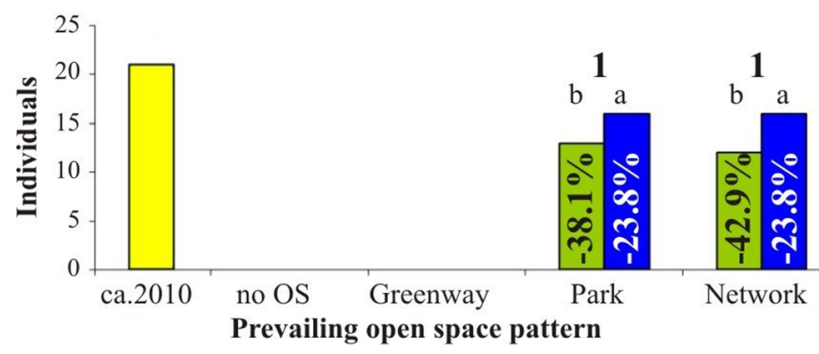

e) Douglas squirrel: Group members
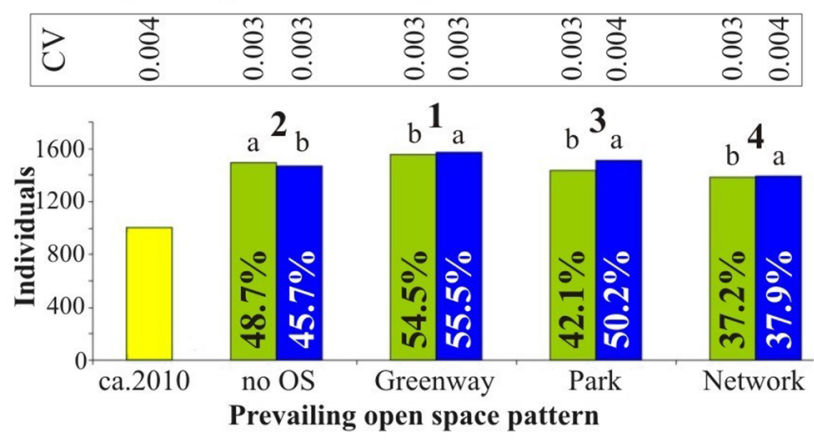

Compact Development

Dispersed Development

Fig. 2 Indicators of population change between ca. 2010 urban reserves and 2060 urbanized landscapes. CV is the coefficient of variation among scenario runs. Numbers on top of bars indicate significant differences among open space patterns; different letters indicate statistically significant differences between compact and dispersed patterns; percentages indicate increase or decrease in population relative to ca. 2010 landscape estimated populations. The horizontal axis shows ca. 2010 conditions and 2060 alternative futures in all charts. Note different b) Red-legged frog: Floaters
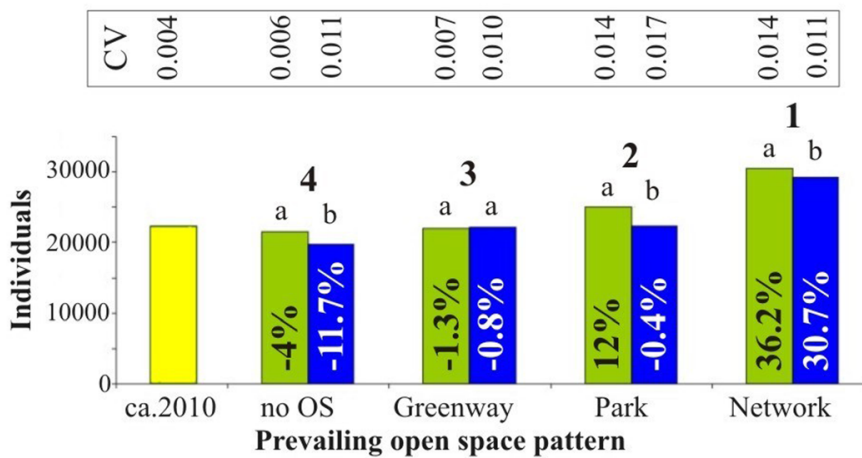

d) Western meadowlark: Floaters

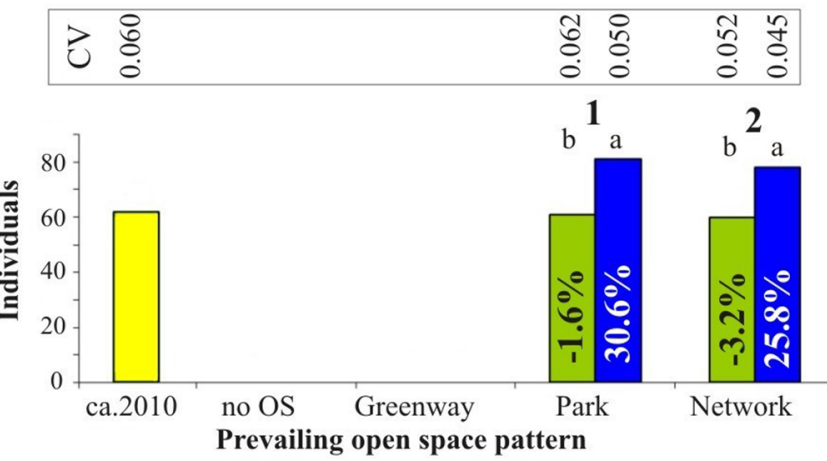

f) Douglas squirrel: Floaters

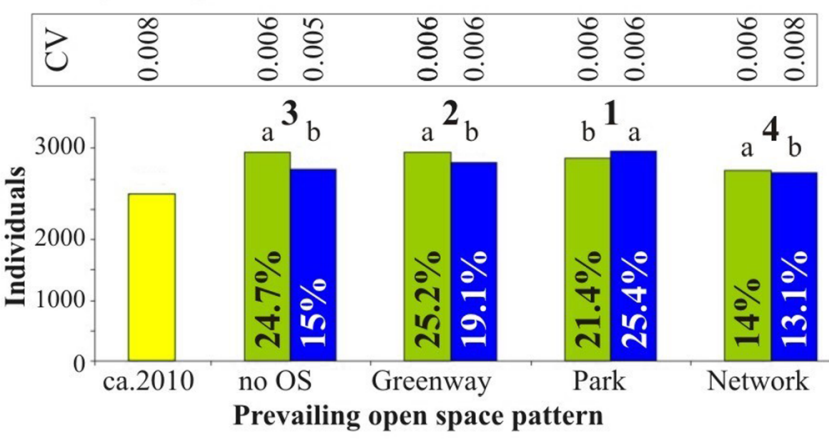

scales on the vertical axes. The first column uses mean scenarios to illustrate landscape change; the second column uses population means among the 20 HexSim runs. a) Red-legged frog Breeding individuals and b) Floaters; c) Western meadowlark Breeding individuals and d) Floaters; and e) Douglas squirrel Breeding individuals and f) Floaters. Breeding individuals are individuals that were able to breed; floaters are those dispersing in search for breeding habitats park scenarios presented larger quantities of floaters. In the future scenarios, breeding individuals means ranged from $12(\mathrm{NCD})$ to 16 (PDD and NDD) individuals. Floaters ranged from 60 (NCD) to 81 (PDD) individuals. NCD scenario presented the large decreases, followed by PCD. PDD and NDD had the smallest decreases of breeding individuals compared to 2010, but the number of floaters increased. 


\section{Douglas squirrel}

There were increases of Douglas squirrel populations in all 2060 scenarios compared to 2010 (Fig. 2e,f). Greenway scenarios had the largest increases of breeding individuals. PDD and GCD scenarios had the largest increases of floaters, while the network scenarios had the smallest increases for both breeding individuals and floaters (Fig. 2e,f). Greenway and park scenarios had the largest proportion of breeding individuals in relation to the total population (33 to $34 \%$ of the total populations are breeding individuals).

In scenarios that adopted open space concepts, all compact development scenarios sustained smaller number of breeding individuals than dispersed development scenarios. Values ranged from 1384 (NCD) to 1569 (GDD) breeding individuals. In the no open space scenarios (CD and $\mathrm{DD}$ ), compact development performed better than dispersed. Floater populations were larger in all compact development scenarios but the PCD scenario. Values ranged from 3107 (NDD) to 3439 floaters (GCD).

\section{Limitations}

Any ecological evaluation model is a simplified representation of ecological processes. This dispersal modeling approach was simple in order to provide data and visualizations of the effects of landscape pattern change on wildlife dynamics. Because it was simple, some realworld qualities were not directly addressed. I used some modeling tools to simulate the effects of some of those qualities.

The simulation used does not include interaction among different species. Red-legged frogs are susceptible to predation and competition with Bullfrogs, which occur in the area as a result of degraded aquatic habitats. In this model, predation of Red-legged frogs by Bullfrogs is implicit in the first year survival rate. Predation by house pets is also indirectly addressed by mortality rates in urban areas, as well as road kill. Urban development projections did not simulate the expansion of the road network. This is particularly important in dispersed development scenarios where new roads should connect urban zones that appear isolated. This may have an impact on results, especially for Redlegged frogs and Douglas squirrels, and is discussed in the next section. Also, the simulation represents year 2060. However, as land cover evolves to natural conditions in protected or restored wetlands, exotic species (e.g. Bullfrogs) find less suitable conditions to thrive. This change is not taken into account in the model.

\section{Discussion}

Results from this study have implications for understanding responses of wildlife species to multiple configurations of an urbanizing landscape. Within the limitations of the model and given the scenario representations, results indicate which scenarios and which combinations of open space and urban development sustain viable populations of the three target species expressed in terms of estimated abundance ca. 2060. Each species is addressed in the next sections.

\section{Red-legged frog}

All scenarios sustained populations of Red-legged frogs. They all have small portions of remaining or restored wetlands that serve as breeding habitats for Red-legged frogs and larger areas of riparian forests used as migratory habitats. The small wetland area relative to the area covered by forests results in proportionally smaller numbers of individuals that find breeding habitats compared to the amount of individuals that are not able to establish breeding habitat and remain browsing the landscape for suitable breeding habitats (floaters).

Network scenarios showed large increases of Red-legged frog populations. The images in Fig. 3 contrast two snapshots from ca. 2010 and Network and Compact Development model runs. Ca. 2010 HexMaps (Fig. 3a-c) show the movements performed by frogs in areas surrounding the larger wetland. Observing simulation runs, it is possible to see individuals moving back and forth without ever reaching other wetlands. Large amounts of Red-legged frog floaters indicate that this species may benefit from urban structures. If appropriately managed, frogs may use sustainable drainageways (COSEWIC 2004; O'Neil 2001) and house yards and parks (Davidson et al. 2001). In contrast, NCD maps (Fig. 3d and e) depict similar movements performed in a landscape where more corridors are present. Because networks are composed of corridors (riparian vegetation) and habitat patches (wetlands), frogs are able to disperse longer distances and reach and colonize other breeding habitats. Although ca. 2010 had already enough breeding habitats to sustain a viable population, it was the improvement of corridors that made it possible for floaters to reach and stablish new breeding habitats in year 2060.

Performance of other scenarios were not as effective as network scenarios because park scenarios lacked the improvement of corridors, while greenway scenarios lacked developing new breeding habitat patches.

\section{Western meadowlark}

Western meadowlarks are scarce in the northern Willamette Valley (where Portland is located) (Myers and Kreager 2010). However, the ca. 2010 simulation showed that the landscape 

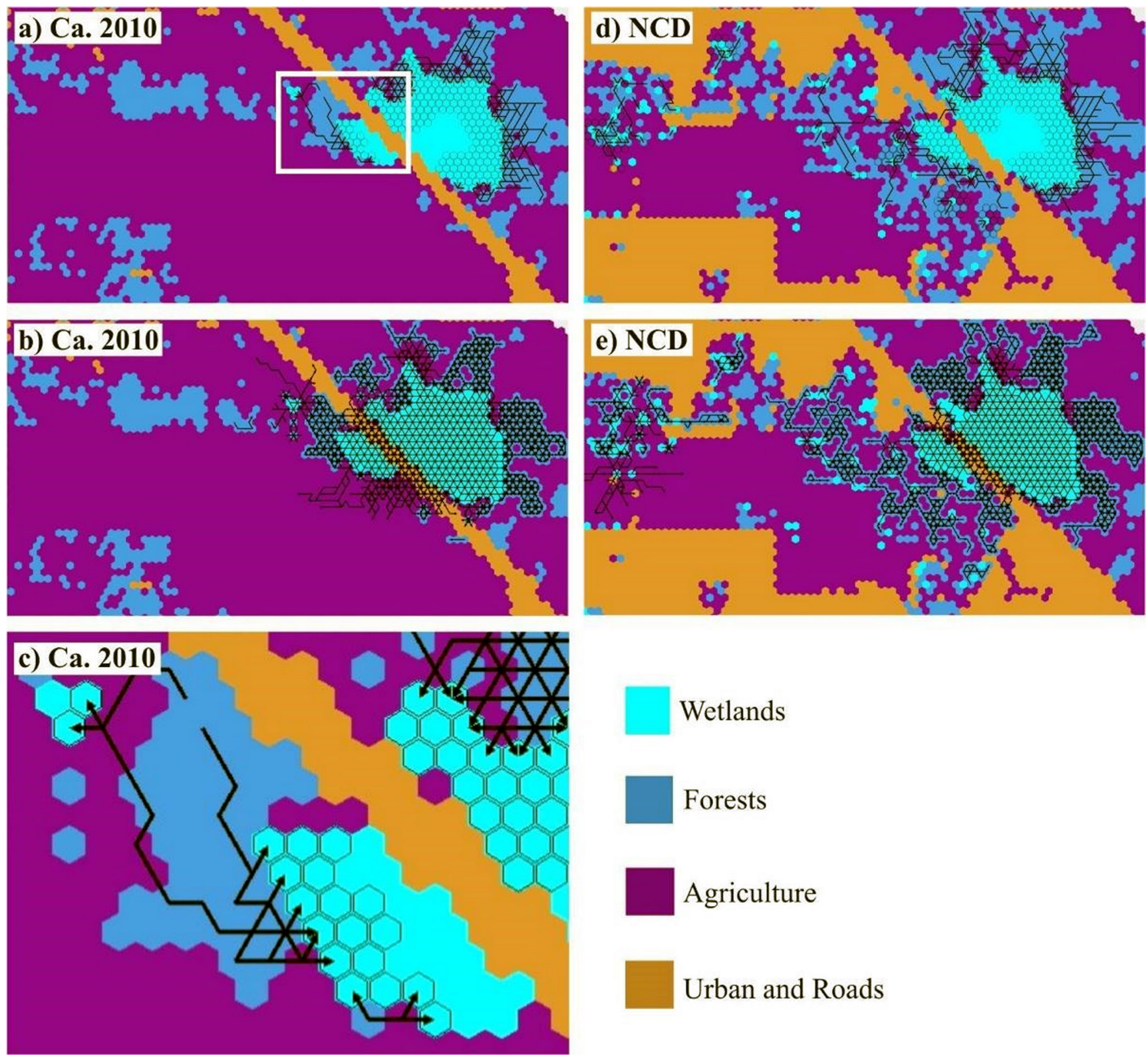

Fig. 3 Red-legged frog suitability maps (HexMaps): a) Ca. 2010 and d) Network and Compact Development Scenario (NCD): small black arrows depict migration from moist forests toward wetlands for breeding while hexagons show individuals exploring areas for

could sustain a mean population of approximately 83 individuals ( 21 breeding individuals and 62 floaters) after simulation reached steady state. In the ca. 2010 landscape, Western meadowlark habitats are dispersed across the landscape in small patches. In four scenarios (no open scape CD and DD, and corridor-based GCD and GDD), simulations started with a population of 1000 individuals and rapidly declined leading to extinction. Because in the development of CD and DD scenarios, no open space spatial concept was applied, and GCD and GDD scenarios focused on vegetated corridors which were represented mostly by riparian corridors -, those scenarios presented small, isolated patches of habitats unable

establishing breeding territories; b) Ca. 2010 and e) NCD: small black arrows depict dispersal of juvenile and adults after breeding; c) enlarged area outlined in a) - each hexagon is $30 \mathrm{~m}$ wide

to sustain breeding individuals of Western meadowlarks. The relatively larger number of floaters indicates that there are suitable habitats for feeding - as the crops mentioned above -, but those birds are not able to find habitat parches large enough for breeding. The lack of large patches of grasslands and oak savannas affected the persistence of meadowlarks in those scenarios.

Four 2060 scenarios sustained reduced but viable populations: patch-based scenarios PCD an PDD, and network scenarios NCD and NDD. These scenarios provided the best patch distribution for the meadowlark. In these scenarios, simulation maps showed a pattern of use that differs from the 
pattern in the ca. 2010 landscape. Here, birds use a group of small close patches (Fig. 4) while in the other four future scenarios birds concentrate in large patches (Fig. 5). This species tends to have large territories that are not necessarily confined to single fields (Frawley 1989). The NCD scenario presented an average 12 breeding individuals after steady state. This scenario presents larger and closer patches that allowed this population to persist. Although the NCD scenario presented the best results, it still had a $42.9 \%$ decrease of population mean compared to ca. 2010 population.

Parameters for dispersal distance adopted in the simulation were large enough to allow birds to colonize other patches within the study area. During simulations, it was possible to observe that birds were able to explore other patches. However, the size of those patches and isolation from large patches apparently prevented Western meadowlarks to establish viable populations. Corridors do not contribute for the conservation of this species, while stepping stones play a fundamental role for dispersal, but birds demand access to larger patches.

Because the model used to produce scenarios (Envision) considers vegetation succession, i.e. the natural change of vegetated habitats to later successional stages, from grasslands to forests, cause habitats for the meadowlarks disappear. Management of grasslands and oak savannas could prevent loss of those habitats. Management of remaining agricultural lands could also include practices that create suitable conditions for grassland birds: "fallow fields, lightly-grazed pastures, grass seed fields, vineyards, and Christmas tree farms can provide habitat for grassland birds and some other wildlife" (Oregon Department of Fish and Wildlife 2006). Various types of open space that include human activities could be managed or adapted to promote Western meadowlark populations. For example, golf courses could also contribute to conservation of bird communities if appropriate design features are adopted (LeClerc and Cristol 2005).

Concentrating rather than dispersing development greatly increases protection of natural systems. Surprisingly, compact development scenarios showed the largest decreases of breeding populations (Fig. 3c) and numbers of floaters increased in dispersed development scenarios (Fig. 3d).

\section{Douglas squirrel}

All scenarios showed an increase in Douglas squirrel populations. Simulations started with small populations -100 individuals. This indicates that there was an improvement of landscape structure in every scenario with increased forests and connections among them.

In fact, it is possible to observe the evolution of occupancy - squirrels that construct territories - by looking at scenario runs (Fig. 6). The HexMap representation of Ca. 2010 (Fig. 6a) shows that there were no urban areas in the studied landscape. The GDD (Fig. 6b) and NDD (Fig. 6c) HexMaps show large extents of urbanized areas in 2060. The ca. 2010 map shows a large amount of breeding habitats interspersed with other forests suitable for movement and foraging. There was a significant reduction of habitats and large urban growth, but the GDD map shows a large, continuous tract of breeding habitats with smaller areas of other forests and other smaller corridors surrounded by the urban matrix. The fifty-year simulated urbanization (in Envision) emulates vegetation

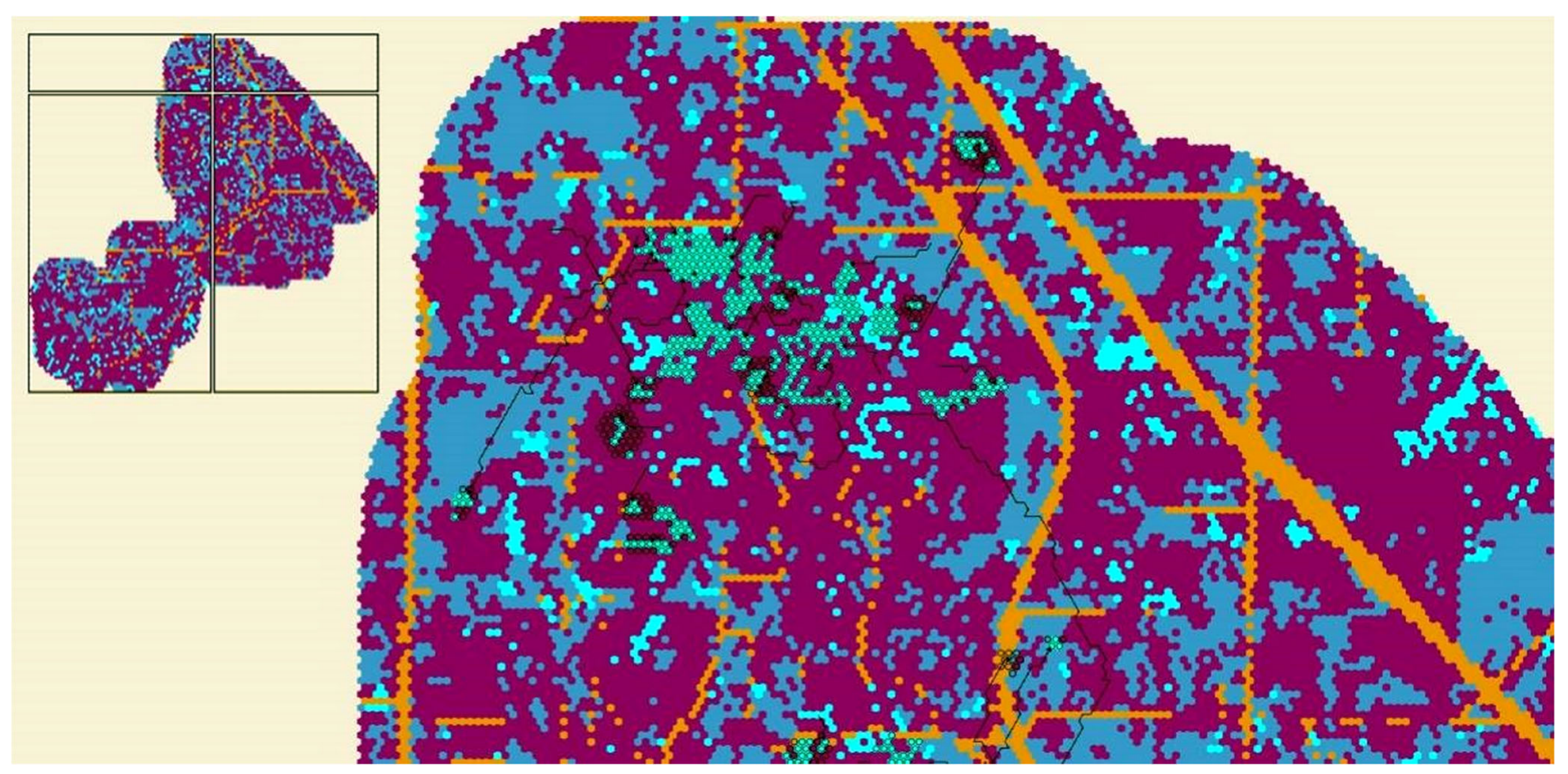

Fig. 4 HexSim representation of a portion of ca. 2010 suitability maps for the Western meadowlark. Birds occupy and disperse to smaller patches 


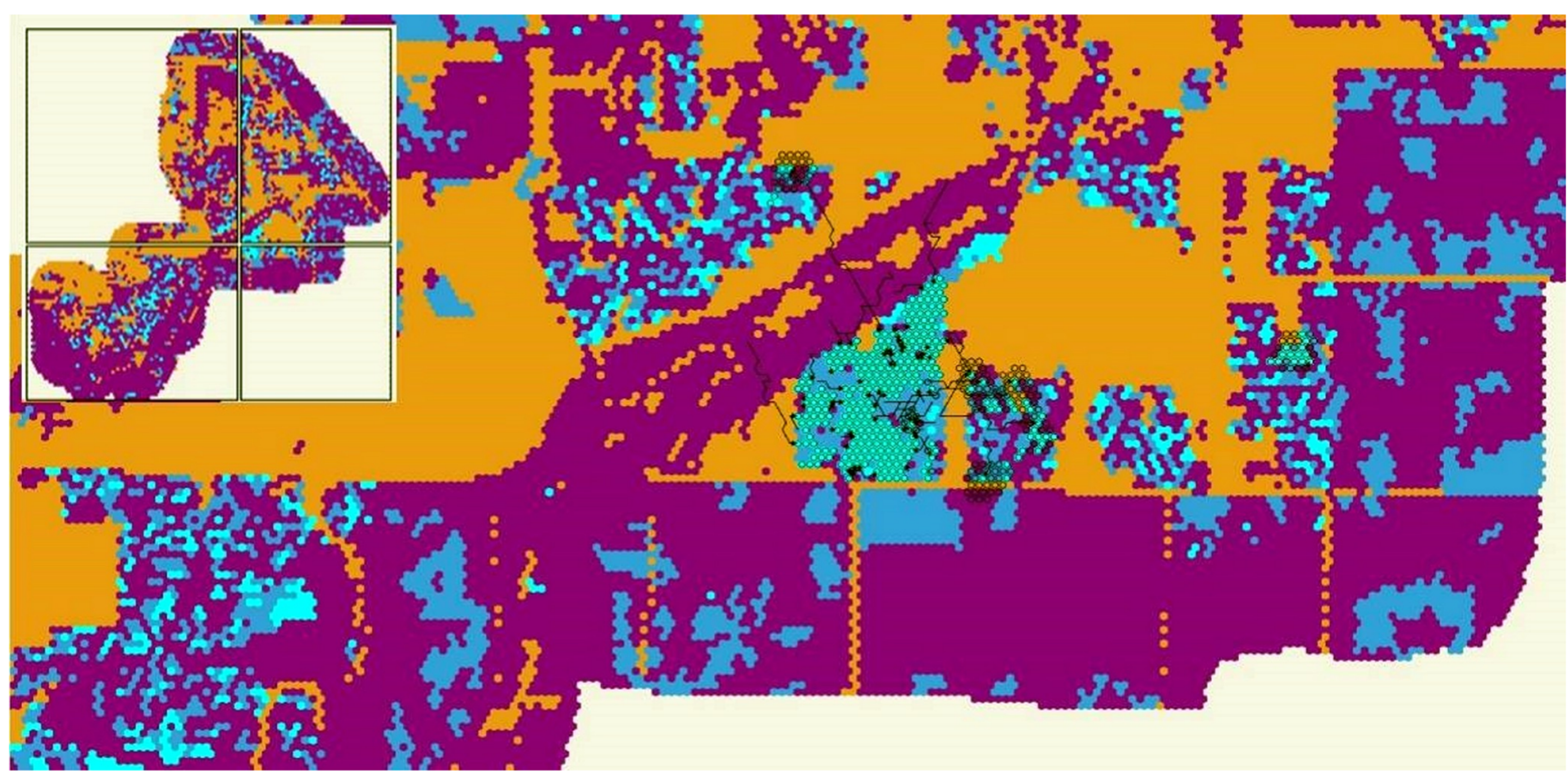

Fig. 5 HexSim representation of a portion of the NCD scenario suitability map. Birds occupy one large patch and disperse to small patches

succession that allows forests to mature, hence creating larger areas of suitable habitats for the Douglas squirrel. The use of a small initial population (100 individuals) permitted observing the evolution of squirrel populations. They mostly dispersed through corridors, but sometimes were able to reach and colonize patches that were in relative isolation from the corridor (Fig. 6c).

Urban growth and the consequent impacts on squirrels road kill and pet predation, for example - did not prevent their population to thrive. Even scenarios with minimal protection of habitats (CD and DD) presented landscape patterns for viable populations of Douglas squirrels.

While network scenarios showed the smallest increases for Douglas squirrel, they presented increases compared to ca. 2010 populations. However, network scenarios performed best for Red-legged frogs and second best for Western meadowlarks (following parks scenario). For Douglas squirrel, greenway scenarios and no open space scenarios performed best and second best respectively. These results indicate that choices for protecting species individually - by adopting their best scenarios - may dramatically affect other species. Western meadowlarks demonstrated being the species most sensitive to change mainly because of their demand for large patches for breeding, what a minimal open space (CD or DD) and a corridor-only approach (GCD and GDD) does not provide. Although not the best for Douglas squirrel, these ca. 2060 network scenarios still promote increased populations relative to ca. 2010 conditions and also support viable populations of Red-legged frogs and Western meadowlarks.

The networks produced in the future scenarios present connected habitat patterns that contain various types of habitats.
This habitat heterogeneity causes network scenarios to not perform best for some indicators, but also leads them to sustain more species (as noted by Opdam et al. 2006). Studies have also demonstrated that diverse urban green areas containing high diversity of vegetation types are rich in bird biodiversity and promote high native bird biodiversity (Callaghan et al. 2019). For Bakker et al. (2015), ecological networks connecting patches of habitat can help species overcome the impacts of land-use change.

The diversity of habitat types provided by the proposed network - which are combinations of parks/fragments and corridors - derived not from a desired drawing or plan but from species life histories may sustain a more diverse assemblage of wildlife species, while other options may result in tradeoffs that compromise species diversity. I conclude, then, that network scenarios are likely to present the best combinations to sustain diversity of species.

\section{Conclusions}

This study investigated how landscape patterns of open space and urban development may affect sensitive wildlife species movements and demographics. The eight future scenarios, each having a different combination of open space and urban development patterns, produced different results for each species. Park and network scenarios presented the best results across all three species. While scenarios with no open space and greenway scenarios presented good results for both the Red-legged frog 

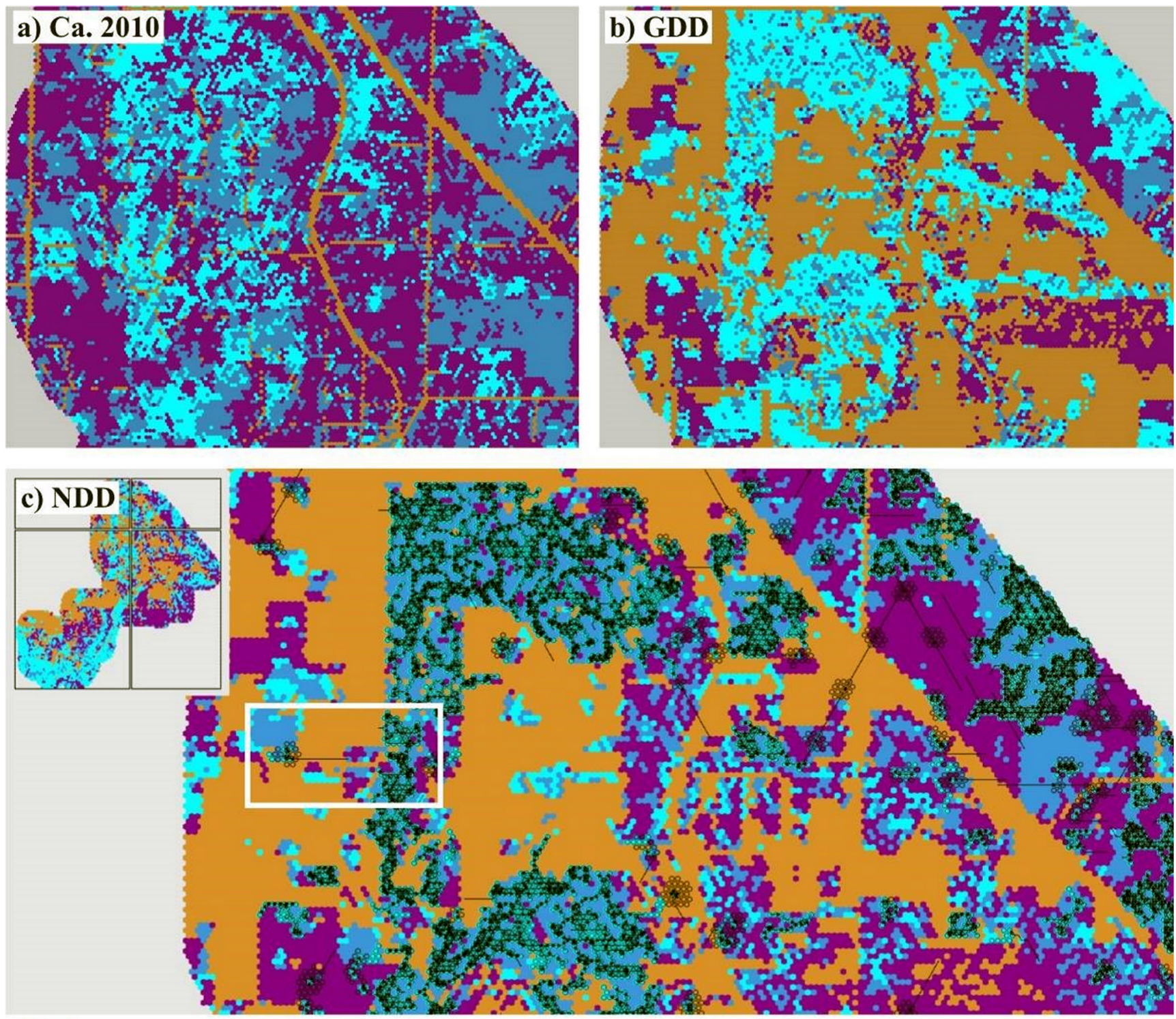

\section{Old growth and mature forests}
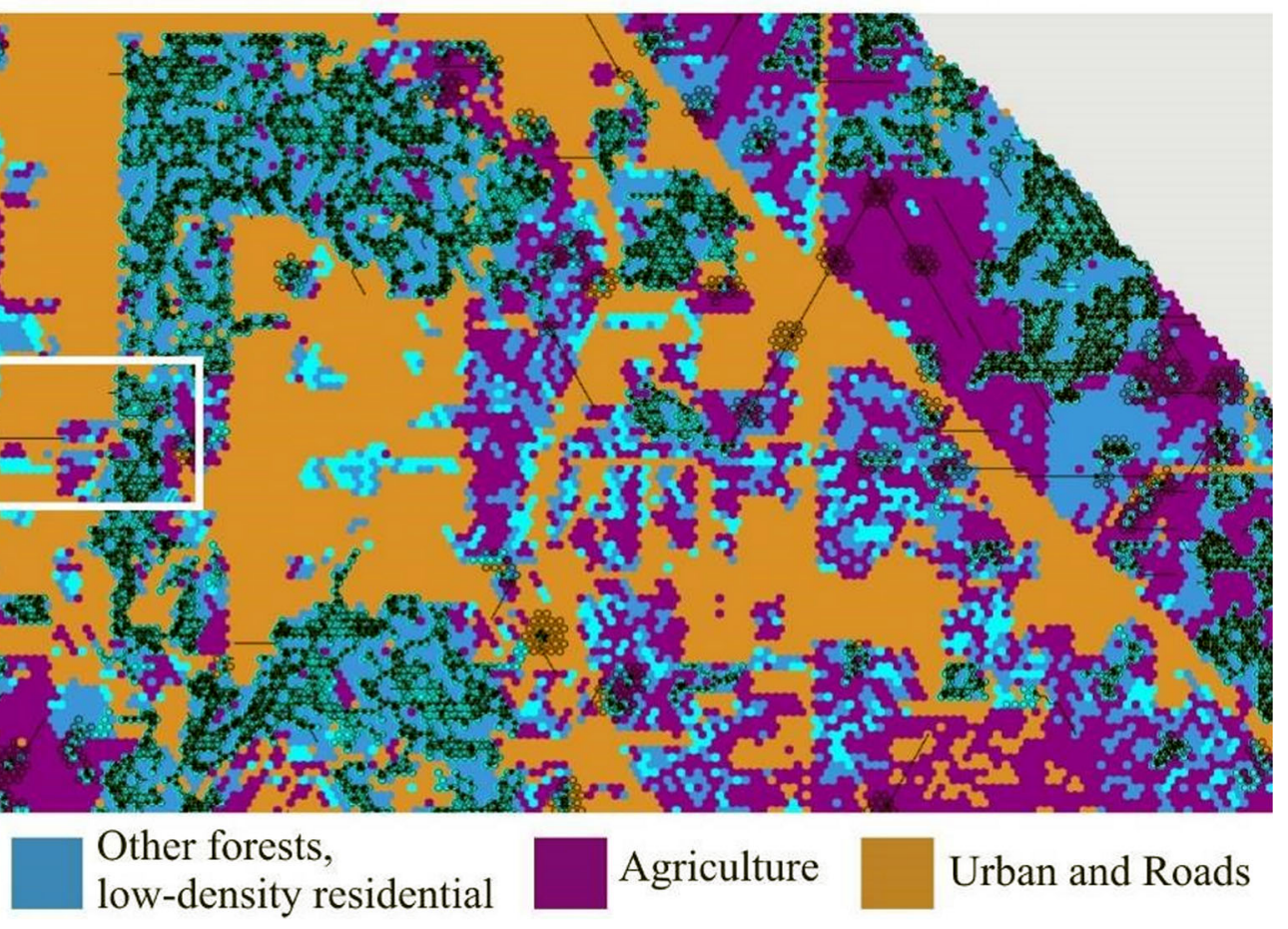

Fig. 6 Douglas squirrel suitability maps (HexMaps): a) Ca. 2010 and b) Greenway and Dispersed Development Scenario (GDD) ca. 2060 show the different habitat patterns; c) occupation and dispersal patterns of

and the Douglas squirrel, these scenarios did not sustain viable populations of Western meadowlarks.

Decisions about wildlife conservation are among many other decisions involved in planning new large expanses of urbanization. A few dispersed development scenarios presented the best results in this assessment, but it is likely that compact development strategies also promote efficient use of infrastructure and sociability, among other benefits (Arendt et al. 1994; Calthorpe and Fulton 2001).

Spatial concepts developed from principles of landscape ecology proved useful for creating a framework of open space. The results show that urban open space

Douglas squirrel in the NDD scenario. Note occupancy and dispersal to smaller, isolated patches (outlined). Inset shows location of the enlarged area in the study area

planning processes can benefit from a deeper understanding of the effects of landscape ecological spatial concepts on wildlife viability. An outcome from this study is the test of an assessment method that can potentially help decision-making in the planning process. As noted by Opdam et al. (2006), quantitative indicators enhance communication with stakeholders and make decision-making more efficient about the outcomes of planning and design. This assessment method may make a valuable contribution in the planning process when choices include preferences for alternative spatial concepts and their effects on wildlife species persistence. 
What is too often lacking in such efforts, and what I proposed here, is a way of assessing how promising proposed spatial arrangements are determined through defensible procedures that could pragmatically fit in a planning process. I evaluate the potential of resulting plans by providing defensible evidence of some of the mechanisms that lead to the statistical differences in the relationships between proposed patterns of urbanization and their biodiversity effects. The results demonstrated that a modeling approach could provide quantitative answers that may meaningfully inform the dialogue among planning stakeholders and, consequently, the quality of decisions. The results also illustrated the degree to which, if designers are relying on simpler, more habitat-based metrics alone, they may be getting a different answer than would be produced by a population viability model. The analysis herein shows where, how, and how much development produces what effects, and, in turn, what to protect through strategies such as land acquisition, protection of agricultural areas and infrastructure design. Therefore, my research approach deals with the fundamental components of landscape structure, composition and configuration.

The use of a wildlife dispersal model (HexSim) to assess the effects of different configurations of land-use and land cover and, by extension, the wildlife habitats they represent, deepens the understanding of the traditionally qualitative use of landscape ecological spatial concepts. I argue that the resulting ecological assessment strengthens the linkages between landscape ecology theory and planning practice.

Supplementary Information The online version contains supplementary material available at https://doi.org/10.1007/s11252-020-01074-3.

Acknowledgments The author thanks David Hulse for his guidance and revisions, Nathan Schumaker for assistance with dispersal modeling, and Bart Johnson for comments and suggestions.

Authors' contributions The author is responsible for the article as a whole.

Funding Financial support was received from the CAPES Foundation (Ministry of Education of Brazil), from the Universidade Federal do Espirito Santo, and from the University of Oregon.

Data availability The research was built upon public open source material and data. The data produced can be made available upon request via email to the author.

\section{Compliance with ethical standards}

Ethics approval and consent to participate Not applicable to this study.

Consent for publication The author gives Urban Ecosystems consent for publication.
Competing interests There are no competing interests.

Financial interests The author declares he has no financial or nonfinancial interests to disclose.

Open Access This article is licensed under a Creative Commons Attribution 4.0 International License, which permits use, sharing, adaptation, distribution and reproduction in any medium or format, as long as you give appropriate credit to the original author(s) and the source, provide a link to the Creative Commons licence, and indicate if changes were made. The images or other third party material in this article are included in the article's Creative Commons licence, unless indicated otherwise in a credit line to the material. If material is not included in the article's Creative Commons licence and your intended use is not permitted by statutory regulation or exceeds the permitted use, you will need to obtain permission directly from the copyright holder. To view a copy of this licence, visit http://creativecommons.org/licenses/by/4.0/.

\section{References}

Ahern J (1999) Spatial concepts, planning strategies and future scenarios: a framework method for integrating landscape ecology and landscape planning. In: Klopatek J, Gardner R (eds) Landscape ecological analysis: issues and applications. Springer-Verlag Inc., New York, pp 175-201

Arendt R, Brabec EA, Dodson HL, Reid C, Yaro RD (1994) Rural by design: maintaining small town character. Planners Press, American Planning Association, Chicago, Ill

Baker JP, Landers DH (2004) Alternative-futures analysis for the Willamette River Basin, Oregon. Ecological Applications 14:311312. https://doi.org/10.1890/02-5008

Bakker MM, Opdam PFM, Jongman RHG et al (2015) Model explorations of ecological network performance under conditions of global change. Landscape Ecol 30:763-770. https://doi.org/10.1007/ s10980-015-0181-9

Bancroft BA, Lawler JJ, Schumaker NH (2016) Weighing the relative potential impacts of climate change and land-use change on an endangered bird. Ecology and Evolution 6:4468-4477

Botequilha Leitão A, Ahern J (2002) Applying landscape ecological concepts and metrics in sustainable landscape planning Landscape and Urban Planning 59:65-93 DOI: https://doi.org/10.1016/S01692046(02)00005-1

Calkin DE, Montgomery CA, Schumaker NH, Polasky S, Arthur JL, Nalle DJ (2002) Developing a production possibility set of wildlife species persistence and timber harvest value. Canadian Journal of Forest Research 32:1329

Callaghan CT, Bino G, Major RE, Martin JM, Lyons MB, Kingsford RT (2019) Heterogeneous urban green areas are bird diversity hotspots: insights using continental-scale citizen science data. Landscape Ecol 34:1231-1246. https://doi.org/10.1007/s10980-019-00851-6

Calthorpe P, Fulton WB (2001) The Regional City: planning for the end of sprawl. Island Press, Washington, DC

Carroll C, Noss RF, Paquet PC, Schumaker NH (2003) Use of Population Viability Analysis and Reserve Selection Algorithms in Regional Conservation Plans. Ecological Applications 13:1773-1789

Carroll C, Noss RF, Paquet PC, Schumaker NH (2004) Extinction Debt of Protected Areas in Developing Landscapes. Conservation Biology 18:1110-1120

Chelgren ND, Rosenberg DK, Heppell SS, Gitelman AI (2006) Carryover Aquatic Effects on Survival of Metamorphic Frogs during Pond Emigration. Ecological Applications 16:250-261 
COSEWIC (2004) COSEWIC assessment and update status report on the Red-legged Frog Rana aurora in Canada. Ottawa.

Davidson C, Shaffer HB, Jennings MR (2001) Declines of the California Red-Legged Frog: Climate, UV-B, Habitat. and Pesticides Hypotheses Ecological Applications 11:464-479

Dramstad WE, Olson JD, Forman RTT (1996) Landscape ecology principles in landscape architecture and land-use planning. Harvard University Graduate School of Design; Island Press; American Society of Landscape Architects, [Cambridge Mass.]; Washington, DC; [Washington, D.C.]

Duncan S (2004) Squirrels cannot live by truffles alone: a closer look at a northwest keystone complex. Science Findings 60

Dunk JR, Woodbridge B, Schumaker N, Glenn EM, White B, LaPlante DW, et al. (2019) Conservation planning for species recovery under the Endangered Species Act: A case study with the Northern Spotted Owl. PLoS ONE 14(1): e0210643. https://doi.org/10.1371/journal. pone. 0210643

Forman RTT (1995) Land mosaics: the ecology of landscapes and regions. Cambridge University Press, Cambridge [England]; New York.

Forman RTT (2004) Mosaico territorial para la region metropolitana de Barcelona. Editorial Gustavo Gili, Barcelona

Forman RTT (2008) Urban regions: ecology and planning beyond the city. Cambridge University Press, Cambridge, UK

Forman RTT, Collinge SK (1997) Nature conserved in changing landscapes with and without spatial planning. Landscape and Urban Planning 37:129-135

Frawley BJ (1989) The dynamics of nongame bird breeding ecology in Iowa alfalfa fields. M.S. thesis. Iowa State University, Ames, Iowa, p 94

Gonzales EK, Wiersma YF, Maher AIN (2008) Positive relationship between non-native and native squirrels in an urban landscape. Canadian Journal of Zoology 86:356-363. https://doi.org/10.1139/ Z08-006

Heinrichs JA, Bender DJ, Gummer DL, Schumaker NH (2010) Assessing critical habitat: Evaluating the relative contribution of habitats to population persistence. Biological Conservation 143:2229-2237

Hulse D, Gregory S, Baker J (2002) Willamette River Basin Planning Atlas: trajectories of environmental and ecological change. Oregon State University Press, Corvallis

Johnson DH, Igl LD (2001) Area requirements of grassland birds: a regional perspective. The Auk 118(1):24-34

Lannoo MJ (2005) Amphibian declines: the conservation status of United States species. University of California Press, Berkeley

LeClerc JE, Cristol DA (2005) Are Golf Courses Providing Habitat for Birds of Conservation Concern in Virginia? Wildlife Society Bulletin 33:463-470

Marcot BG, Raphael MG, Schumaker NH, Galleher B (2013) How big and how close? Habitat patch size and spacing to conserve a threatened species. Nat Resour Model 26:194-214

McCauley LA, Ribic CA, Pomara LY, Zuckerberg B (2017) The future demographic niche of a declining grassland bird fails to shift poleward in response to climate change. Landscape Ecol 32:807-821. https://doi.org/10.1007/s10980-017-0487-x

McRae BH, Schumaker NH, McKane RB, Busing RT, Solomon AM, Burdick CA (2008) A multi-model framework for simulating wildlife population response to land-use and climate change. Ecological Modelling 219:77-91

Metro (1992). Metropolitan Greenspaces Master Plan: a Cooperative Regional System of Natural Areas, Open Space, Trails and Greenways for Wildlife and People Portland, OR: Metro.

Morrison G (1993) Western meadowlark. Hortic 71(8):57

Myers AM and Kreager A (2010) Declining and State Sensitive Bird Species Breeding in Willamette Valley Grasslands: 2008/09 Status Update Oregon Department of Fish and Wildlife.
Ndubisi F (2002) Managing Change in the Landscape: A Synthesis of Approaches for Ecological Planning. Landscape Journal 21(1):138 155

Nogeire-McRae T, Lawler JJ, Schumaker NH, Cypher BL, Phillips SE (2019) Land-use change and rodenticide exposure trump climate change as the biggest stressors to San Joaquin kit fox. PLoS ONE 14(6):e0214297. https://doi.org/10.1371/journal.pone.0214297

O’Neil TA (2001) Matrixes for Wildlife-habitat relationships in Oregon and Washington. Northwest Habitat Institute, Corvallis

Opdam P, Steingrover E, Rooij SV (2006) Ecological networks: A spatial concept for multi-actor planning of sustainable landscapes. Landscape and Urban Planning 75:322-332. https://doi.org/10. 1016/j.landurbplan.2005.02.015

Oregon Department of Fish and Wildlife (2006) The Oregon Conservation Strategy. Oregon Dept. of Fish and Wildlife, Salem

Penteado HM (2013) Assessing the effects of applying landscape ecological spatial concepts on future habitat quantity and quality in an urbanizing landscape. Landscape Ecol 28, 1909-1921. https://doi. org/10.1007/s10980-013-9940-7

Ransome DB, Sullivan TP (2004) Effects of food and den-site supplementation on populations of Glaucomys sabrinus and Tamiasciurus douglasii. Journal of Mammalogy 85:206-215. https://doi.org/10. 1644/BOS-118

Rottle, N, Maryman, B (2006) Envisioning Seattle's Green Future Seattle, WA: Open Space Seattle 2100 Project.

Rubino MJ, Hess GR (2003) Planning open spaces for wildlife 2: modeling and verifying focal species habitat. Landscape and Urban Planning 64:89-104. https://doi.org/10.1016/S0169-2046(02) 00203-7

Schumaker N, Ernst T, Haggerty P, Baker J, White D (2002) Terrestrial wildlife - populations. In: Hulse D, Gregory S, Baker J (eds) Willamette River Basin Planning Atlas: trajectories of environmental and ecological change. Oregon State University Press, Corvallis, pp 126-127

Schumaker NH (1996) Using Landscape Indices to Predict Habitat Connectivity. Ecology 77:1210-1225

Schumaker NH (2011) HexSim (Version 2.1). Corvallis, OR.

Schumaker NH, Brookes A (2018) HexSim: a modeling environment for ecology and conservation. Landscape Ecol 33:197-211. https://doi. org/10.1007/s10980-017-0605-9

Schumaker NH, Ernst T, White D, Baker J, Haggerty P (2004) Projecting wildlife responses to alternative future landscapes in Oregon's Willamette Basin. Ecological Applications 14:381-400

Steinitz C (2001) Landscape ecology and landscape planning: Links and gaps and common dilemmas. Publicaciones Instituti Geographici Universitatis Tartuensis 92:48-50

Stronen A, Schumaker N, Forbes G, Paquet P, Brook R (2012) Landscape resistance to dispersal: simulating long-term effects of human disturbance on a small and isolated wolf population in southwestern Manitoba, Canada. Environmental Monitoring Assessment 184:6923-6934

Sullivan TP, Sullivan DS (1982) Population Dynamics and Regulation of the Douglas Squirrel (Tamiasciurus douglasii) with Supplemental Food. Oecologia 53:264-270

Termorshuizen JW, Opdam P, and van den Brink A (2007) Incorporating ecological sustainability into landscape planning. Landscape and Urban Planning, 79(3-4), 374-384.

The R Foundation for Statistical Computing. (2011) R (Version 2.14.1).

Ward EM, Wysong K, Gorelick SM (2020) Drying landscape and interannual herbivory-driven habitat degradation control semiaquatic mammal population dynamics. Ecohydrology. 13:e2169. https:// doi.org/10.1002/eco.2169

Wiens JD, Schumaker NH, Inman RD, Esque TC, Longshore KM, Nussear KE (2017) Spatial demographic models to inform conservation planning of Golden Eagles in renewable energy landscapes. J Raptor Res 51:234-257 